\title{
Click Chemistry: Versatility and Control in the Hands of Materials Scientists**
}

\author{
By Himabindu Nandivada, Xuwei Jiang, \\ and Joerg Lahann*
}

The increasing need for materials with tightly controlled structures will continue to fuel the induction of synthetic organic concepts into materi-

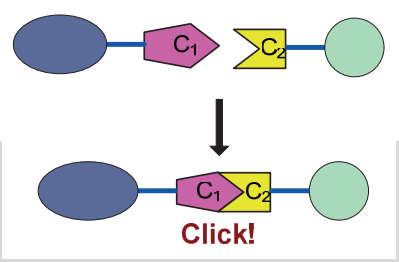
als science. One powerful example is the embracement of "click chemistry" by the materials science community. Because of their high selectivity, near-perfect reliability, high yields, and exceptional tolerance towards a wide range of functional groups and reaction conditions click reactions have recently attracted increased attention, specifically for use in polymer synthesis as well as for the modification of surfaces and nanometer-and mesoscale structures. As outlined in this Review article, click chemistry, such as the $C u^{I}$-catalyzed Huisgen 1,3-dipolar cycloaddition and the Diels-Alder reaction, presents a synthetic concept that lends itself superbly to the controlled preparation of multifunctional materials.

\section{Introduction}

Current advances in our understanding of molecular biology, microelectronics, and sensorics have fueled increasing needs for materials with more sharply defined structures; ${ }^{[1]}$ however, the preparation of such materials imposes major synthetic challenges. In fact, many of the currently used processes to synthesize materials allow only crude control over the structure of the material. As a consequence, man-made materials often do not match the superb properties of natural materials such as proteins, DNA, or sugars. To address this gap between the sophisticated functionality that is required for future advances in bio- and nanotechnology and the limited chemical control offered by many of the synthetic materials processes that are currently available, we are now witnessing an increasing infusion of synthetic organic chemistry

[*] Prof. J. Lahann, H. Nandivada, X. Jiang Departments of Chemical Engineering and Materials Science and Engineering, and Macromolecular Science and Engineering University of Michigan

2300 Hayward Street, Ann Arbor, MI 48109 (USA)

E-mail: lahann@umich.edu

[**] J.L. gratefully acknowledges support from the NSF in form of a CAREER grant (DMR-0449462). concepts into materials science. ${ }^{[1]}$ This trend appears to be motivated by the prospect of molecular-level control during the preparation of nanostructured materials. In spite of the evident differences between small molecules and macromolecules, attempts to extend synthetic concepts from organic chemistry into the nanometer- and mesoscale dimensions have been increasingly fruitful. For a synthetic organic concept to be applicable to the preparation of macromolecules, the reactions must i) result in a stable linkage, ii) exhibit minimal cross-reactivity with other functional groups, iii) react to completion, iv) be free of appreciable amounts of side products, and v) proceed under benign reaction conditions.

Sharpless and others have recently developed a framework of reactions that is often referred to as "click chemistry". ${ }^{[2]}$ This synthetic framework, which fulfills all of the above-mentioned criteria, may have great potential for use in the synthesis of materials. As such, click reactions are driven by a high thermodynamic force $\left(>20 \mathrm{kcal} \mathrm{mol}^{-1}\right)$, which gives rise to highly modular and stereospecific reactions with high yields. In that sense, click chemistry is not limited to a specific type of reaction (e.g., Friedel-Crafts acylation or Baeyer-Villiger oxidation) but rather defines a synthetic concept or framework that comprises a range of reactions, with different reaction mechanisms, but common reaction trajectories. In fact, Sharpless defined click chemistry early on as the generation of complex substances by bringing together smaller units via 
heteroatoms. ${ }^{[2]}$ While a range of chemical reactions can in principle fulfill these criteria, successful examples often originate from five broad classes of reactions that appear to fit the framework of click chemistry exceptionally well: ${ }^{[2]}$

1. Cycloaddition of unsaturated species: 1,3-dipolar cycloaddition.

2. Cycloaddition of unsaturated species: [4+2]-cycloaddition (Diels-Alder).

3. Nucleophilic substitution/ring-opening reactions.

4. Carbonyl reactions of the non-aldol type.

5. Addition to carbon-carbon multiple bonds.

In this Review, we will restrict ourselves to the first two types of reactions only, that is, the role of cycloadditions of unsaturated species in materials science (Scheme 1). We will discuss recent advances with respect to both 1,3-heterocycloadditions as well as [4+2]-cycloadditions. Similarities be- tween the two reactions regarding synthetic versatility, benign reaction conditions, high yields, and functional group tolerance will be highlighted from the perspective of a materials scientist.

\section{Results}

\subsection{Role of Click Chemistry in Preparing Nanomaterials}

Only a few years after the formal introduction of the concept of click chemistry, its importance to materials science, and more specifically polymer synthesis, was demonstrated experimentally on the basis of triazole dendrimer synthesis. ${ }^{[3]}$ Despite some noteworthy restrictions of 1,3-dipolar cycloadditions, such as the need for $\mathrm{Cu}^{\mathrm{I}}$ catalysts and the limitation to
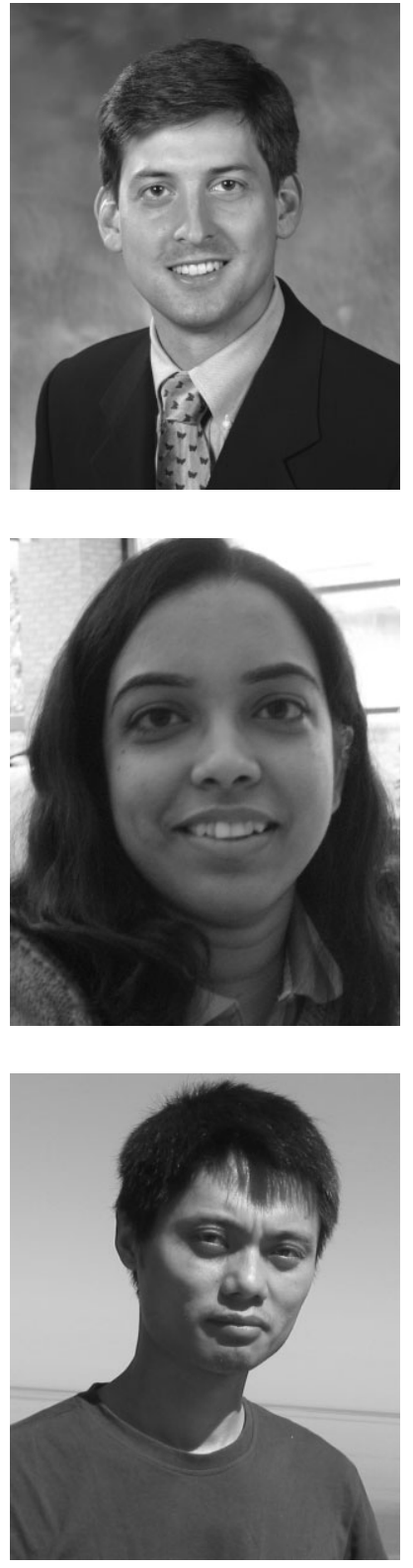

Joerg Lahann is the Dow Corning Assistant Professor in Chemical Engineering at the University of Michigan. His research interest is focused on the development of synthetic strategies that bring together concepts from materials science and biotechnology. He received his Ph.D. from the RWTH Aachen, Germany, in Macromolecular Chemistry under the guidance of Prof. H. Hoecker. After working as a postdoctoral researcher with Prof. R. Langer at the Massachusetts Institute of Technology, he joined the departments of Chemical Engineering, Materials Science and Engineering, and Macromolecular Engineering at the University of Michigan in 2003. He has been selected by Technology Review magazine as one of the top 100 young innovators with the greatest potential to have an impact on technology in the 21st century. He is also a Recipient of the 2006 DOD Idea award and an NSF-CAREER award. He is the author of more than 45 publications and 19 patents or patent applications.

Himabindu Nandivada is pursuing her Ph.D. in the Department of Chemical Engineering at University of Michigan, Ann Arbor (MI). She obtained her M.Sc. in Chemical Engineering from the University of Michigan-Ann Arbor in 2005 and B.Tech. in Chemical Engineering from the Indian Institute of Technology, Kanpur (India) in 2003. Her current research interests include developing immobilization strategies for designing biofunctional surfaces via reactive coatings.

Xuwei Jiang is a postdoctoral research fellow in the Department of Chemical Engineering at the University of Michigan. He received his Ph.D. in Polymer Chemistry from Michigan State University under the guidance of Prof. G. L. Baker in 2006. His current research interests include surface-initiated polymerizations (SIPs), molecular switches, and immobilization strategies for designing biofunctional surfaces via reactive coatings. 


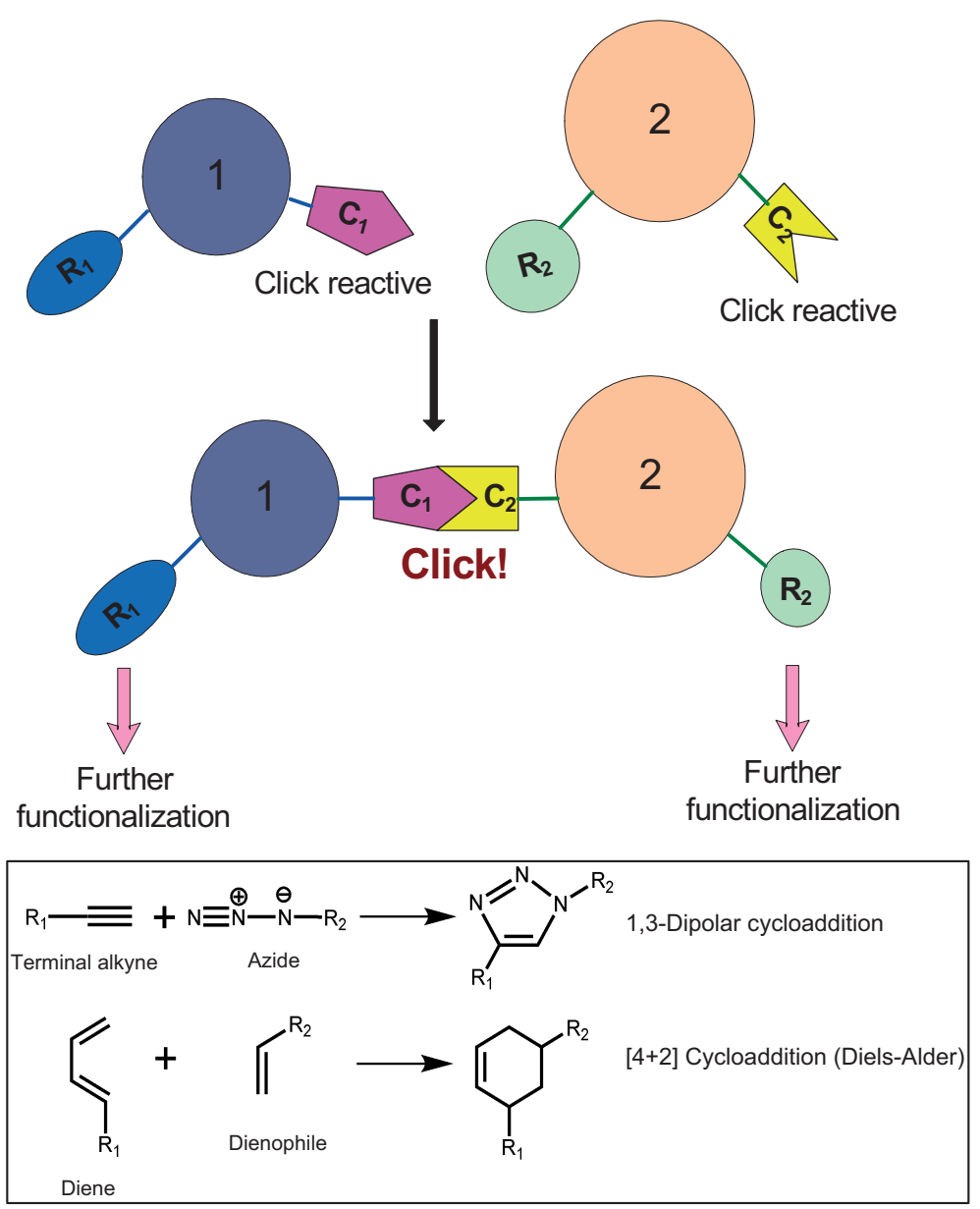

Scheme 1. Multifunctional design of materials by using "click chemistry" reactions, such as 1,3-dipolar and [4+2] (Diels-Alder) cycloadditions.

terminal alkynes, a wide range of novel materials characteristics were realized soon after the application of click reactions to materials science. ${ }^{[3-16]}$ For example, Adronov and co-workers coupled alkyne-functionalized spacers to single-walled carbon nanotubes (SWNTs) via amine groups. ${ }^{[17]}$ In this example, the use of click chemistry for chemical functionalization of SWNTs provided a new access route to nanomaterials that were otherwise difficult to purify. The presence of the alkyne groups did not interfere with the initial coupling, but enabled highly specific post-synthesis modification, as demonstrated by subsequent reaction with azide-terminated polystyrene. This method granted a greater level of control over the orientation and the density of the polymer attached to the surface of the nanotube while reducing the risk of side reactions.

Similarly, Diels-Alder reactions have been used for selective modification of carbon nanotubes. For example, $o$-quinodimethane was directly coupled to SWNTs with the help of microwave irradiation (Fig. 1). ${ }^{[18]}$ These reactions open up possibilities for enhancing the solubility of carbon nanotubes, as needed in several technological applications. ${ }^{[17]}$

Taking advantage of either Huisgen's 1,3-dipolar cycloadditions or Diels-Alder reactions, a range of different methods were further developed for modification of $\mathrm{Au}$ nanoparticles. ${ }^{[19-23]}$ One intriguing example is based on directed hydrogen-bonding systems that were covalently immobilized onto self-assembled monolayers of alkanethiols by using Huisgen's cycloaddition reaction. ${ }^{[19]}$ In a subsequent step, $\mathrm{Au}$ nanoparticles were bound to these anchors through the formation of multiple hydrogen bonds. Another approach used a Diels-Alder reaction for the immobilization of unsaturated DNA strands onto maleimide-coated $\mathrm{Au}$ nanoparticles. ${ }^{[20]}$ Selfassembled nanoparticles can be further used for biosensor applications or supramolecular assemblies. Taking advantage of the extreme selectivity of the alkyne-azide reaction, these concepts can readily be extended to the functionalization of metal and metal-oxide nanoparticles. ${ }^{[21,24]}$

\subsection{Role of Click Chemistry in Surface Engineering}

At the heart of the concept of using click reactions for the controlled modification of Au surfaces is the intrinsic compatibility of the participating binding partners with the presence of free thiol groups. The compatibility with thiol and disulfide groups makes click reactions similarly important for microstructuring of flat noble-metal surfaces, because thiols and disulfides can be bound to gold or silver surfaces, forming well-defined self-assembled monolayers (SAMs). ${ }^{[25]}$ Recently, several advances have been made with respect to the preparation of SAMs containing azido groups on well-defined electrode surfaces and subsequent reaction with ethynyl ferrocene or propynone ferrocene. ${ }^{[26]}$ Chidsey and coworkers also used the 1,3-dipolar cycloaddition reaction to develop a selective procedure for creating well-defined surface arrays of acetylene-containing oligonucleotides onto azidefunctionalized SAMs on gold. ${ }^{[2]}$ This chemistry was shown to be fairly immune to deactivation by electrophiles or nucleophiles and stable against hydrolysis. Similarly, 1,3-dipolar cycloadditions on acetylenyl-terminated SAMs and azide compounds were used as a versatile tool for tailoring surface functionalities under mild conditions. ${ }^{[28-30]}$ For example, Huisgen's dipolar cycloaddition was employed to immobilize azide-functionalized sugars (mannose, lactose, and $\alpha$-galactose) onto alkyne-terminated SAMs on gold (Fig. 2) ${ }^{[31]}$ It was found that these carbohydrate-based sensors maintained their specificity towards the corresponding proteins, which could lead to potential applications in high-throughput characterization of carbohydrate-protein interactions.

In a very elegant approach reported by Mrksich's group, hydroquinone groups in SAMs were electrochemically oxidized into quinone groups that, in turn, underwent Diels-Alder reaction. ${ }^{[32]}$ The unique aspect of this approach is that these sys- 


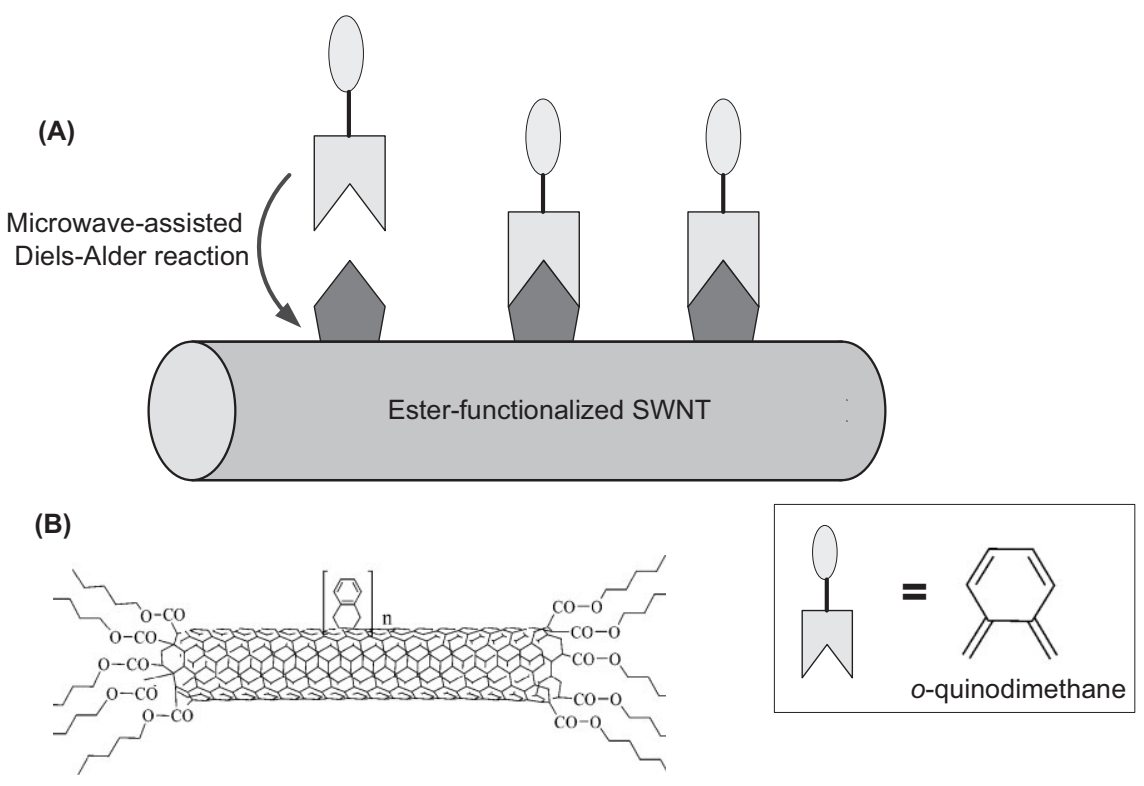

Figure 1. A) Schematic illustration of the functionalization of SWNTs by using a Diels-Alder reaction between quinodimethanes and ester-functionalized SWNTs under microwave irradiation. B) Structure of a modified SWNT. Reproduced with permission from [18]. Copyright 2004 The Royal Society of Chemistry.

tems can react on demand, as they are turned "on" through the initial electrochemical reaction step. Alternatively, monolayers presenting nitroveratryloxycarbonyl-protected (NVOC) hydroquinones were photochemically cleaved to reveal the hydroquinone groups (Fig. 3). ${ }^{[3]}$ These activated groups were reversibly oxidized to the corresponding benzoquinones, which were then used to immobilize diene-functionalized ligands (such as cell adhesion peptides) via Diels-Alder reaction.

More recently, Huisgen's click chemistry by microcontact printing was demonstrated on azide-functionalized SAMs. ${ }^{[34]}$
Reinhoudt and co-workers first treated bromo-terminated SAMs with $\mathrm{NaN}_{3}$, creating an azide-terminated monolayer. Next, octadecyne was printed onto the monolayer by using a poly(dimethylsiloxane) PDMS stamp. The azide-functionalized surface was also reacted with fluorescently labeled alkynes. This microcontact printing approach was conducted in the absence of the copper catalyst, because the high local concentration of reagents in the vicinity of the stamp and the monolayer were believed to be sufficient for the completion of the reaction. ${ }^{[34]}$ The authors suggested that one of the advantages of this strategy is the elimination of the copper catalysts, because copper in higher concentrations is typically considered cytotoxic, and separation of the catalyst after click reaction can be cumbersome. Alternatively, the strain-induced 1,3-dipolar cycloaddition of cyclic alkynes with azides has been recognized as a possibility to eliminate the copper catalyst and to potentially develop more biologically benign materials. $^{[35]}$

Because of their tolerance towards a wide range of unprotected chemical groups, click reactions have been widely used to immobilize sugars, proteins, DNA, and even cells. DielsAlder cycloadditions have proven to be very successful in attaching proteins and cell-adhesion ligands and, consequently, attachment of cells. ${ }^{[36-38]}$ Alternatively, biomolecules such as proteins and carbohydrates were immobilized onto solid substrates by using sequential Diels-Alder cycloaddition and alkyne-azide cycloaddition. ${ }^{[39]}$ A variety of ligands such as bio-
(A)

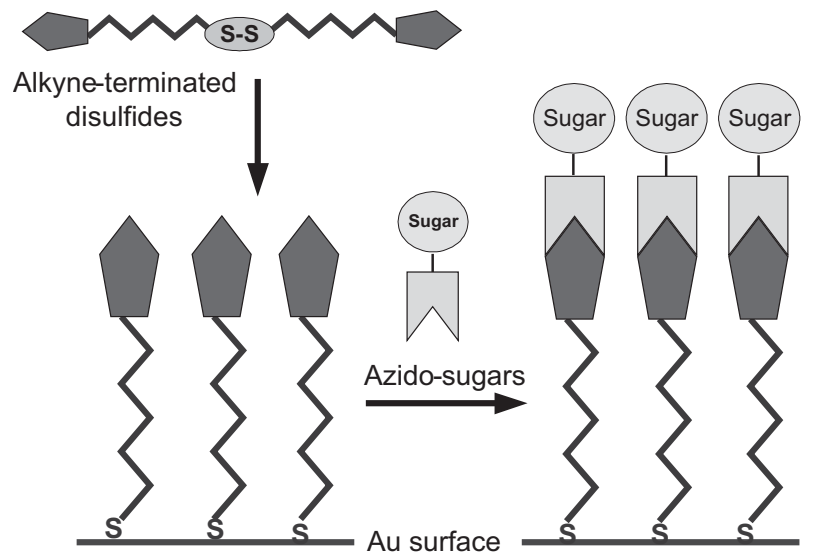

(B)

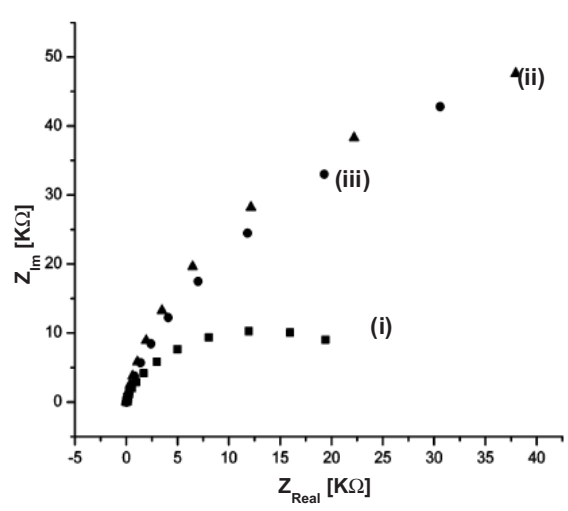

Figure 2. A) Strategy for the immobilization of azide-derivatized carbohydrates on alkyne-functionalized SAMs using 1,3-dipolar cycloaddition. B) Nyquist plots for i) alkyne-SAMs incubated with streptavidin-fluorescein isothiocyanate (FITC), ii) alkyne SAMs + azido-mannose incubated with streptavidin-FITC, and iii) alkyne SAMs + azido-mannose + azido-glycol incubated with streptavidin-FITC. Reproduced with permission from [31]. Copyright 2006 American Chemical Society. 


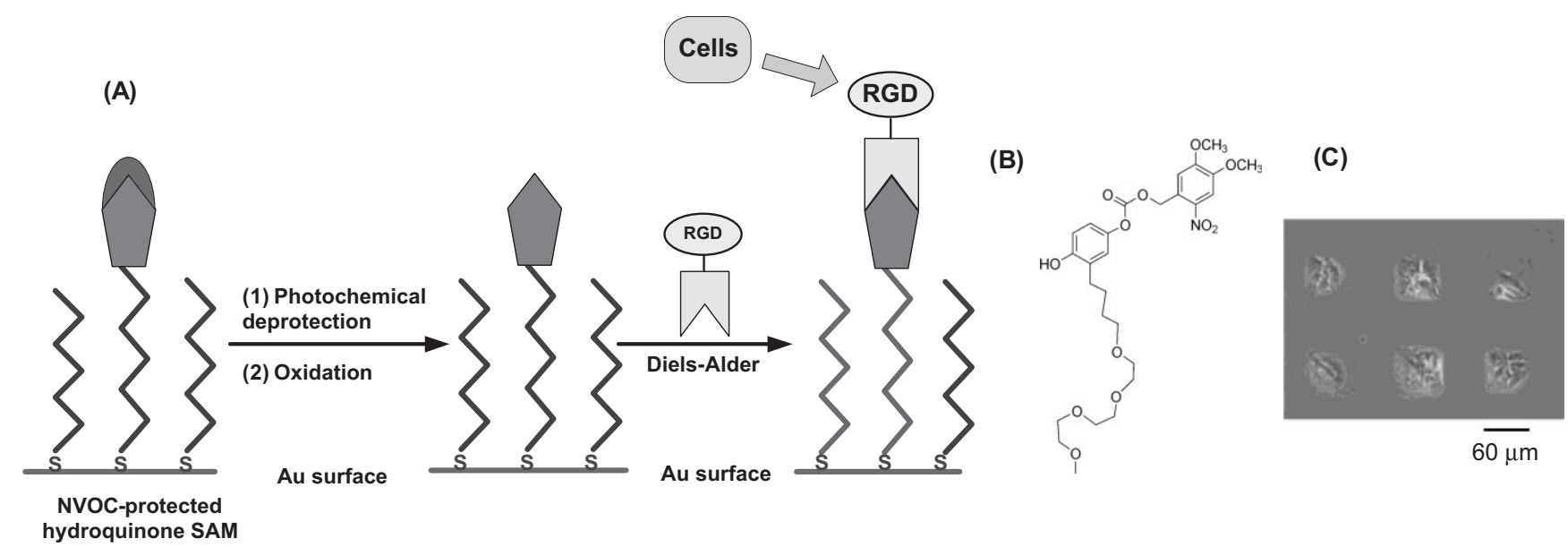

Figure 3. A) Strategy for the immobilization of ligands to SAMs via Diels-Alder cycloaddition. An NVOC-protected hydroquinone SAM is photochemically deprotected, and a cyclopentadiene-ligand conjugate is immobilized via Diels-Alder reaction. B) Structure of the NVOC-protected SAM. C) Cells attached to patterned regions modified with RGD via click chemistry. Reproduced with permission from [33]. Copyright 2004 American Chemical Society.

tin, lactose, and recombinant thrombomodulin protein were attached by using this dual approach (Fig. 4). Similarly, DielsAlder cycloaddition was used for the bioconjugation of dienemodified oligonucleotides, carbohydrates, and proteins. ${ }^{[40-43]}$ The power of this reaction has been further demonstrated by the successful homogeneous ${ }^{[44]}$ and heterogeneous ${ }^{[45]}$ modification of polysaccharides. The mild reaction conditions have even allowed the modification of long DNA fragments without DNA cleavage. ${ }^{[4]}$

On the other hand, the Huisgen 1,3-dipolar cycloaddition reaction was used in a novel strategy for covalent attachment of desired proteins to solid surfaces. ${ }^{[47]}$ Azides were attached to the protein via enzymatic posttranslational modification at the C-terminus, which then enabled further immobilization onto alkyne-functionalized agarose beads. In addition, the Huisgen cycloaddition reaction was employed for the development of an efficient system for the immobilization of complex azide-saccharides to microtiter plates via lipid alkyne tethers. ${ }^{[48]}$ The resulting surfaces were used for screening of specific interactions with proteins. In work done by the same group, azide-functionalized sugars were captured and covalently attached onto microtiter plates via an orthogonal linker that also contained a disulfide cleavage site, to facilitate the analysis of the glycan array using standard mass spectrometry methods. ${ }^{[49]}$ Similarly, both Diels-Alder and Huisgen cycloadditions were used to functionalize porous silicon substrates in an attempt to develop substrates for mass spectrometry applications. ${ }^{[00,51]}$

Recently, alkyne-containing vapor-deposited polymer coatings were shown to possess remarkable reactivity towards azide-functionalized moieties. ${ }^{[52]}$ The reactive coating, poly(4ethynyl- $p$-xylylene-co-p-xylylene), was applied to a wide range of substrates by using chemical vapor deposition (CVD), and modified by subsequent spatially directed 1,3-dipolar cycloaddition reaction. A thin layer of azide-functionalized biotin was preadsorbed onto the polymer-coated sub-
(A)

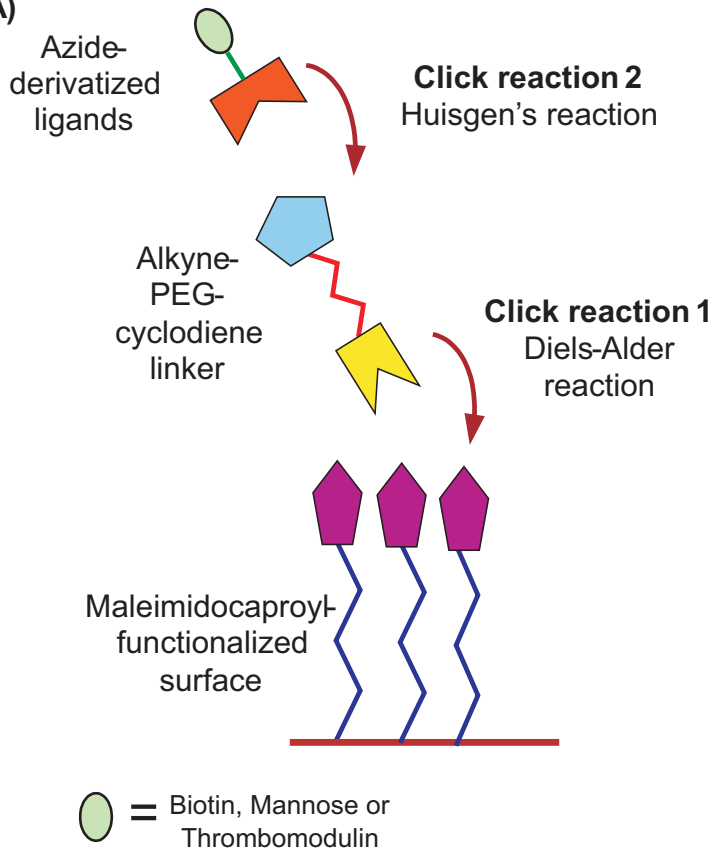

(B)

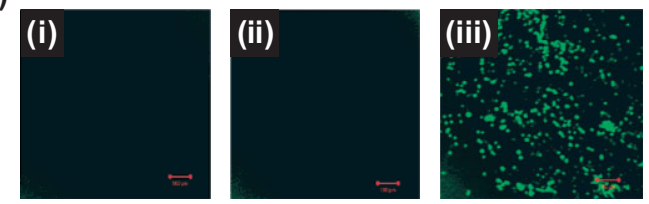

Figure 4. A) Schematic illustration of the applicability of sequential Diels-Alder and alkyne-azide cycloaddition reactions for the immobilization of ligands (biotin, mannose, or thrombomodulin) onto maleimidefunctionalized surfaces. B) Confocal images of i) a maleimide surface incubated with streptavidin-FITC, ii) an alkyne-derivatized surface (produced after click reaction 1) incubated with streptavidin-FITC, and iii) a biotinylated surface (produced after click reactions 1 and 2) incubated with streptavidin-FITC. Reproduced with permission from [39]. Copyright 2006 American Chemical Society. 
strate and the copper catalyst was then microcontact-printed, resulting in a spatially controlled surface modification. The alkyne groups on the polymer surface acted as anchors for the immobilization of azido-biotin, which was further used for the binding of streptavidin (Fig. 5). The azido-biotin selectively bound to regions where the catalyst was present. This regioselective immobilization strategy could find applications in the fields of biomedical device coatings, biosensors, and diagnostics.

The 1,3-dipolar cycloaddition reaction was further used as a linking tool in layer-by-layer (LbL) assembly of poly-(acrylic acid) (PAA) multilayer films. ${ }^{[53]}$ First, azide- and alkyne-functionalized PAAs were synthesized via living radical polymerization. The substrates were then sequentially exposed to PAA-azide and PAA-alkyne solutions containing copper catalyst, creating single-component noncharged layers stabilized by the triazole linkages. This can not be achieved by conventional LbL assembly, which is based on charge and/or hydrogen-bonding effects.

\subsection{Role of Click Chemistry in Multifunctional Polymer Design}

The value of click chemistry for materials synthesis perhaps becomes most apparent in the area of polymer chemistry, and several recent reviews describe the use of $\mathrm{Cu}^{\mathrm{I}}$-catalyzed Huisgen cycloadditions for the synthesis of dendritic, branched, linear, or cyclic co-polymers. ${ }^{[54]}$ Hawker, Sharpless, Fokin, and co-workers first introduced the Huisgen reaction to polymer chemists by using it for the synthesis of dendrimers. ${ }^{[3]}$ In their approach, triazole-based dendrons were divergently synthe- sized using the Huisgen cycloaddition as the actual generation-growth step. These dendrons were then convergently anchored to a variety of polyacetylene cores to generate dendrimers (Fig. 6). Since then, this Huisgen cycloaddition has been widely employed to synthesize or modify various dendrimers. ${ }^{[11,14,15,55-61]}$ Similarly, Diels-Alder reactions have found application in dendrimer synthesis and modification. McElhanon and Wheeler prepared dendrons and dendrimers that had thermoresponsive properties, owing to the reversibility of the Diels-Alder reaction. ${ }^{[62]}$ Kim et al. introduced different functional groups onto carbosilane dendrimers with high efficiency. ${ }^{[63-65]}$ In a recent report, the combination of Diels-Alder reaction and decarbonylation was shown to enable the efficient synthesis of shape-persistent desymmetrized polyphenylene dendrimers. ${ }^{[6]}$ This approach also enabled the separation of two regioisomeric polyphenylene dendrimers ${ }^{[66]}$ and allowed the selective attachment of peptides to specific sites within a 3D dendritic structure. ${ }^{[67]}$

It was quickly recognized that the use of click reactions is not limited to the synthesis and functionalization of dendrimers, but is also very useful for the synthesis of a range of functionalized polymers. The remarkable functional-group tolerance of click reactions enabled the facile introduction of reactive groups, such as hydroxyl and carboxyl groups, through conventional pre- ${ }^{[10,68]}$ or post-polymerization modification. ${ }^{[69]}$ The high yield and specificity of click chemistry have not only allowed the quantitative introduction of various functional groups onto polymer backbones, but also enabled both simultaneous and cascade functionalizations of a variety of macromolecules. ${ }^{[54]}$ As an example, the successful functionalization of a terpolymer of 8:1:1 styrene:p-(acetylene)styrene:2-(hydroxymethyl)methacrylate by combining click chem-

(A)

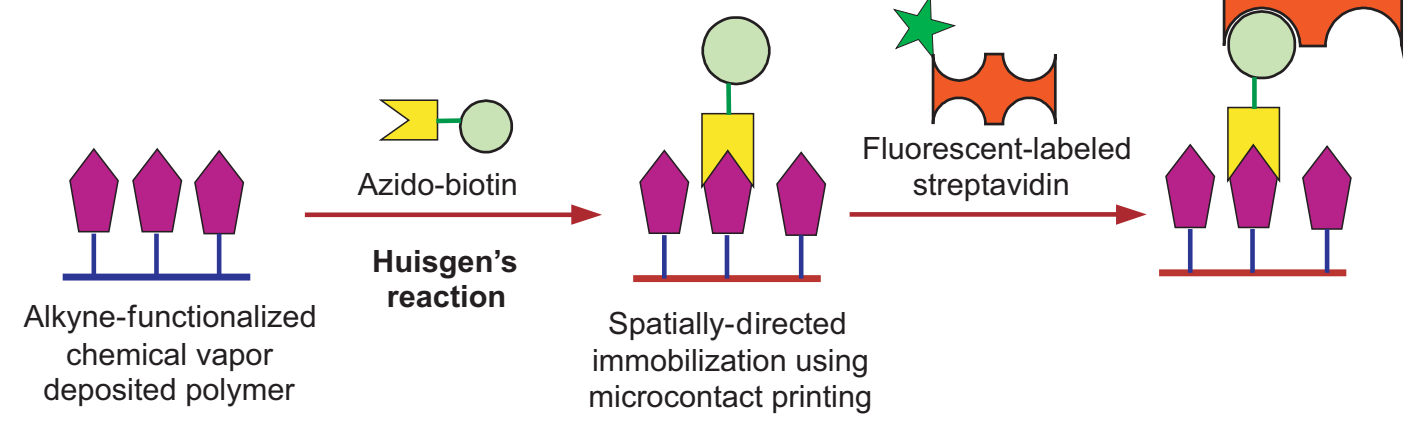

(B)

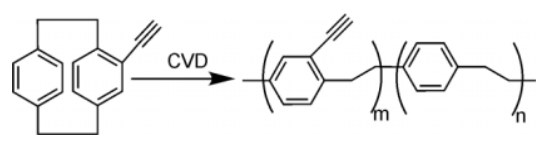

(C)
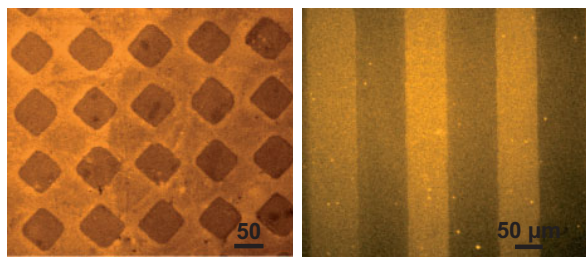

Figure 5. A) Strategy for the immobilization of azide-derivatized biotin on vapor-deposited alkyne-functionalized coating using microcontact printing. B) Synthesis of alkyne-functionalized polymer via CVD of alkyne-functionalized [2.2]paracyclophane. C) Fluorescence microscopy images showing the binding of FITC-streptavidin to patterns of biotin azide on alkyne-functionalized CVD polymer film. Reproduced with permission from [52]. 

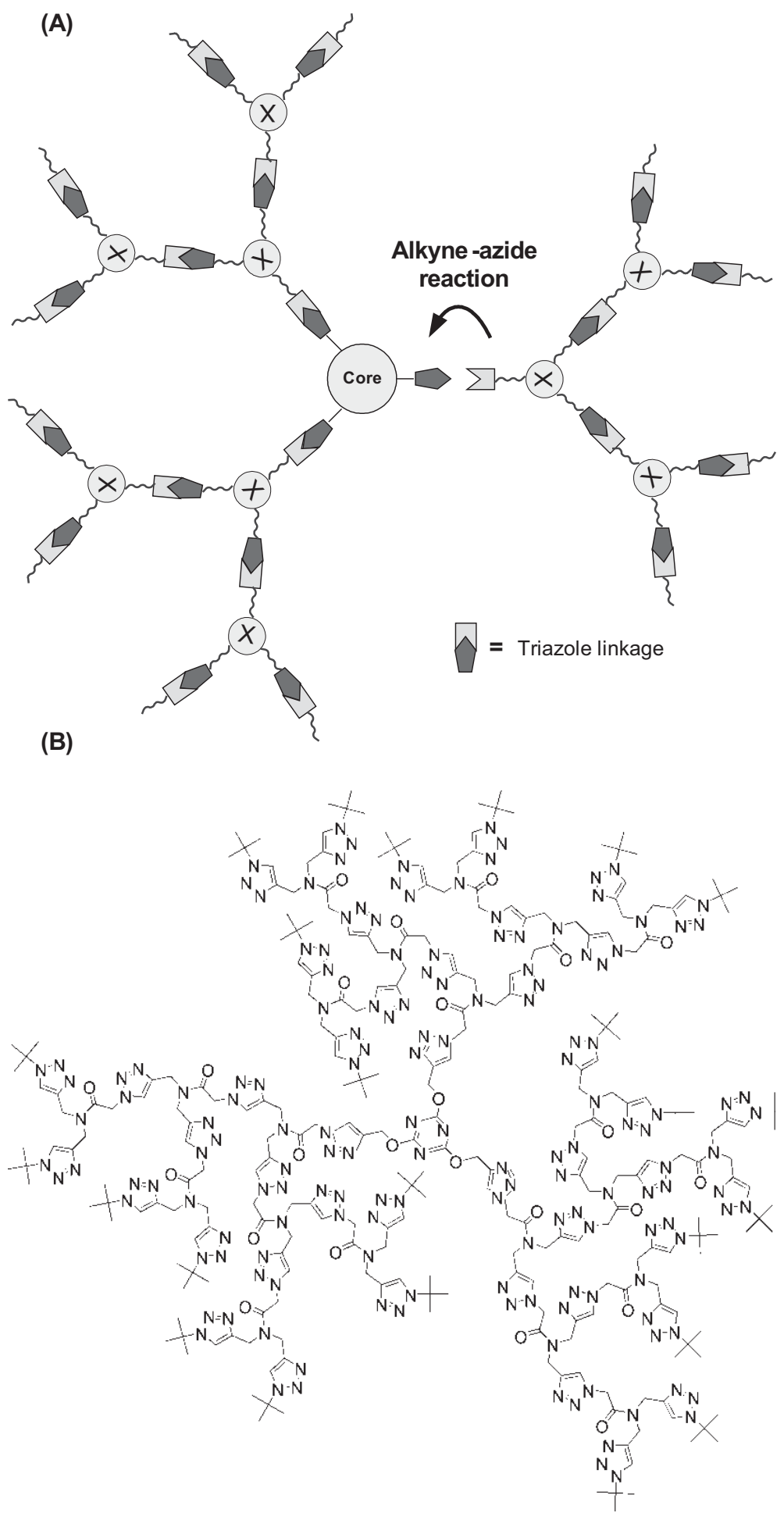

Figure 6. A) Schematic illustration of the generation of diverse dendritic structures by using 1,3-dipolar cycloaddition reaction. B) Example of a dendritic structure synthesized using this click reaction. Reproduced with permission from [3].

istry and alcoholysis of anhydride has been carried out to yield a difunctional polymer in a one-pot synthesis. ${ }^{[16]}$ Triblock copolymers of poly(ethylene glycol), polystyrene, and poly(methyl methacrylate) were synthesized in a one-pot method via a combination of Diels-Alder and 1,3-dipolar cycloaddition. ${ }^{[70]}$

The use of click reactions has been extremely fruitful when combined with living polymerization techniques, such as ring-opening polymerization (ROP), ring-opening metathesis polymerization (ROMP), cationic polymerization, nitroxide-mediated radical polymerization (NMP), atom transfer radical polymerization (ATRP), and reversible addition fragmentation chain transfer polymerization (RAFT). In many of these cases this merger resulted in functional polymers with highly defined structures. In fact, the combination of click chemistry with one or more of these polymerization methods can provide facile access to a broad range of polymeric materials that are otherwise very difficult to prepare. For example, aliphatic polyesters, an important class of biodegradable polymers, are easily degradable during post-polymerization modifications owing to the labile nature of the backbone. The mild reaction conditions required for click chemistry readily allowed its combination with ROP, leading to pendant-group functionalized polyesters $^{[71-73]}$ and starshaped polyesters ${ }^{[74]}$ without backbone degradation.

The efficient combination of click chemistry with ROMP has also led to functional polymers with very high functional-group tolerance. ${ }^{[75]}$ This modular synthetic approach was used to synthesize side-chain-modified poly(oxynorbornene)s through pre- and post-polymerization modifications (Fig. 7). In addition, this combination of click chemistry with cationic polymerization generated water-soluble poly(2-oxazoline)s; promising moieties for targeted drug delivery. ${ }^{[76]}$

Recent work that combined click chemistry with $\mathrm{NMP}^{[12,77]}$ or RAFT ${ }^{[78,79]}$ showed that the 1,3-dipolar cycloaddition reaction between alkynylshell-functionalized block copolymer micelles and polyvalent azides can be used to generate shellcrosslinked nanoparticles. The available sites for chemical modification provided by the crosslinker allowed for further attachment of biologically important moieties to the nanoparticles. ${ }^{[12]}$ Moreover, the selective introduction of the click reactive groups in either the hydrophobic or hydrophilic domain of amphiphilic core/shell nanomaterials has enabled regioselective click functionalization within nanostructures. ${ }^{[77,78]}$ Recently, azido-functionalized RAFT chain-transfer agents were synthesized and used to mediate RAFT polymerizations to prepare various telechelics. ${ }^{[80]}$

In addition to these examples, the most successful combination so far has been the "marriage" of click chemistry with ATRP, partially because the introduction of azide groups via 


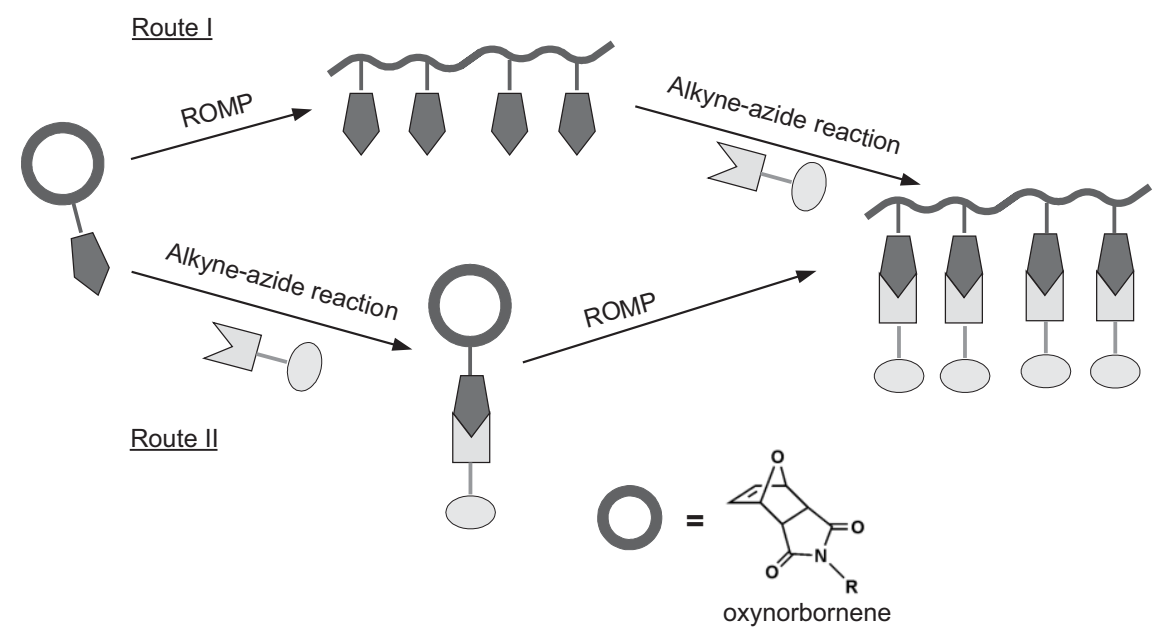

Figure 7. Outline of two approaches combining ROMP and alkyne-azide reaction to prepare functional poly(oxynorbornene)s. Route I: Synthesis of homopolymers with azido or alkyne side chains using ROMP and subsequent 1,3-dipolar cycloaddition. Route II: Attachment of ligands using an alkyne-azide click reaction followed by ROMP [75].

halide precursors is synthetically very straightforward. By using a click-chemistry-ATRP combination and a bifunctional initiator, $\alpha, \omega$-dihydroxypolystyrene was successfully prepared. ${ }^{[81]}$ Using click chemistry, various functional groups (such as carboxyl, olefin, and amine) were attached to the ends of polymers prepared by ATRP, and biomolecules were further attached to the polymer chain ends. ${ }^{[82-84]}$ When an un- saturated difunctional initiator was used, the resulting telechelic polymer was coupled with a crosslinker to yield degradable model networks (Fig. 8). ${ }^{[8]}$ The click coupling of telechelic polystyrene prepared by ATRP yielded a linear polystyrene that contained ester bonds in the backbone, ${ }^{[85]}$ rendering the polymer partially biodegradable. Similar strategies were also applied to the synthesis of various block copolymers, ${ }^{[86]}$ star polymers, ${ }^{[87]}$ miktoarm stars and mikto dendritic copolymers, ${ }^{[88]}$ and well-defined macromonomers ${ }^{[89]}$ from building blocks prepared by ATRP. Recently, even cyclization reactions were carried out on the telechelic styrenic polymers prepared by ATRP, affording macrocycles in nearly quantitative yields. ${ }^{[00]}$ Furthermore, the versatility of ATRP allowed the preparation of both azido- and alkynyl-appended homopolymers, which led to an interesting family of side-chain-functionalized polymers. ${ }^{[91,92]}$ Similar to the Huisgen cycloaddition, the Diels-Alder reaction was also successfully combined with ATRP and NMP for the preparation of macromolecules with complicated structures by Tunca and co-workers. ${ }^{[93]}$ Diblock copolymers were easily prepared by Diels-Alder reaction between maleimide-

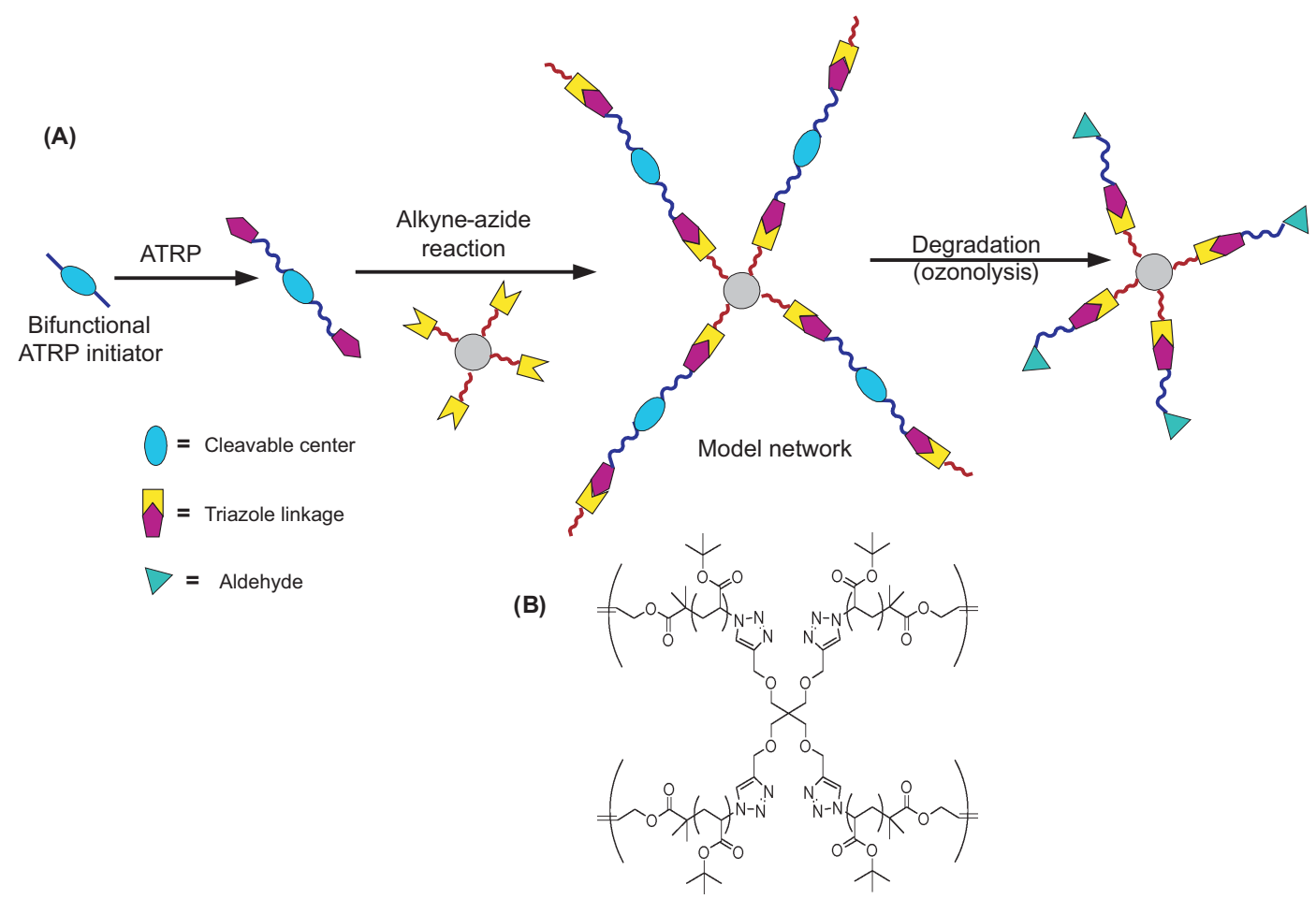

Figure 8. A) Schematic illustration of the use of a bifunctional ATRP initiator containing a cleavable olefin moiety and a multi-acetylene-functionalized molecule to prepare acrylate model networks. This network degrades in the presence of ozone and forms star polymer products. B) Structure of a fourarmed polymeric model-network. Reproduced with permission from [8]. Copyright 2006 American Chemical Society. 
and anthracene-functionalized polymers, which were individually prepared by ATRP. In cases where anthracene end-functionalized prepolymers were prepared by the combination of ATRP and NMP using anthracene-containing ATRP and an NMP bifunctional initiator, the Diels-Alder reaction afforded ABC miktoarm star terpolymers. ${ }^{[94]}$ This approach further led to the formation of $\mathrm{H}$-shaped terpolymers by the simple replacement of the maleimide end-functionalized block with a bismaleimide. $^{[95]}$

Click reactions have not only been used in the synthesis and modification of functionalized polymers, but have also played an important role in the crosslinking of polymeric materials. One such example is the appearance of crosslinked polymeric adhesives synthesized from polyvalent azide and alkyne building blocks, which owe their adhesiveness to the strong affinity of triazoles for metal ions and surfaces. ${ }^{[5]}$ In another example, because of the large amount of tertiary amine groups, the reaction between a trivalent alkyne and a bisazide led to acidswellable crosslinked networks. ${ }^{[9]}$ Similarly, Hilborn and Ossipov reported the synthesis of poly(vinyl alcohol) (PVA)-based hydrogels by mixing azido-appended PVA and acetylene-appended PVA in the presence of a $\mathrm{Cu}^{+}$catalyst (Fig. 9). ${ }^{\text {[96] }}$

The flexibility of this approach possibly allows its extension to other hydroxyl-containing polymers. Well-defined PEGbased hydrogels with improved properties were prepared by Hawker and co-workers using Huisgen cycloaddition. ${ }^{[13]}$ They also showed that this approach allowed network formation in the presence of a variety of additives, which are generally not compatible with the traditional crosslinking conditions for hydrogel preparation. As a thermally controllable reaction, Diels-Alder cycloadditions have been receiving increased at-

(A)
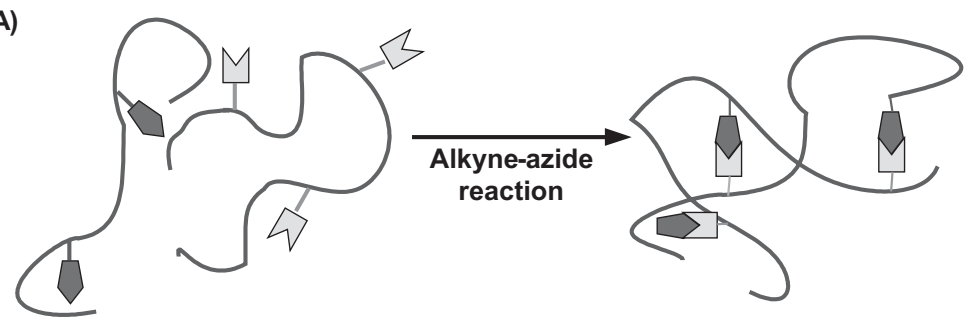

(B)

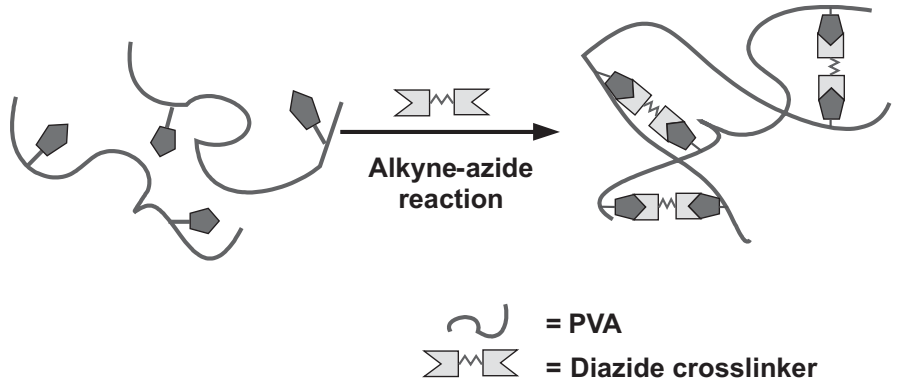

Figure 9. Schematic illustration of the approaches used to prepare PVA-based hydrogels using 1,3-dipolar cycloaddition reactions. A) Azide- and alkyne- modified PVA crosslinked by mixing the solutions in the presence of a $\mathrm{Cu}$ catalyst. B) Alkyne-functionalized PVA crosslinked using a bifunctional poly(ethylene glycol)-diazide crosslinker [96]. tention in cases where reversibility is desirable. Saegusa and co-workers reported the first thermally reversible covalently crosslinked hydrogel by using furan- or maleimide-appended polyoxazoline prepolymers in Diels-Alder reactions. ${ }^{[97]}$ Later, the same prepolymer system was used to prepare thermally reversible interpenetrating polymer networks (IPN) of organic-inorganic nanocomposites. ${ }^{[98]}$ Along the same lines, Jen and co-workers recently reported a styrenic polymer functionalized with dienes, protected dienophiles, and nonlinear optical (NLO) chromophores as pendant groups. ${ }^{[99]}$ By combining Diels-Alder and retro-Diels-Alder reactions a reversibly crosslinkable NLO polymer system was prepared, while avoiding the nonlinearity-stability trade-off. In addition, Diels-Alder reaction of polymeric dienes with dienophiles or polymeric dienophiles with dienes were also useful. For example, poly(ethylene terephthalate) copolymers containing anthracene were prepared. ${ }^{[100]}$ Subsequent Diels-Alder reactions of these copolymers with difunctional maleimides caused grafting, chain extension, and crosslinking. In analogy, Diels-Alder reaction of these copolymers with monofunctional maleimides also enabled the modification of both bulk and surface properties of poly(ethylene terephthalate) (PET).${ }^{[101]}$ By adopting a similar strategy, it was shown that optical properties of anthryl-based poly(phenylene ethynylene)s were tunable through controlled Diels-Alder reactions. ${ }^{[102]}$ Jen and co-workers appended anthracene moieties onto polymer backbones and the subsequent Diels-Alder reaction allowed the introduction of NLO chromophores and cross-linking, leading to a series of new NLO polymers free of ionic species and catalysts. ${ }^{[103]}$ This approach also showed promise in the preparation of various graft copolymers. ${ }^{[104]}$ Other crosslinked polymeric materials such as polystyrene copolymers, ${ }^{[105]}$ acrylates-based and siloxane-based elastomers ${ }^{[106]}$ were also synthesized using this strategy. In these cases, linear side chain functionalized polymers were recovered in high yields by heating the crosslinked network in the presence of an appropriate cross-linker trap. ${ }^{[105,106]}$ With the recently increased interest in self-healing polymeric materials, Wudl and co-workers demonstrated that thermally reversible Diels-Alder polymerization of multidienes and -dienophiles can lead to highly crosslinked, thermally controlled polymeric networks with mechanical properties comparable to those of commercial thermoplastics. ${ }^{[107]}$ This strategy has been further extended to the preparation of polymeric materials for nanometer-scale probe lithography and data storage. ${ }^{[108]}$

\section{Conclusions}

The potential of click chemistry for materials synthesis has been increasingly recognized, and has already resulted in wide range of beautiful manifestations. Specifically, for the synthesis of multi- 
functional materials with a range of different, possibly competing functional side groups, the extraordinary control offered by click reactions has produced a series of novel materials with, in some cases, unique properties. To illustrate this point, a few examples are given on how click chemistry can be used for the application-driven design of functional materials with interesting properties: i) Complete functionalization of alkyne-appended poly $(p \text {-phenyleneethynylene })^{[68]}$ followed by quantitative attachment of phosphorescent iridium complexes $^{[109]}$ and flavin ${ }^{[110]}$ to azido-functionalized polystyrene copolymers has been achieved via click chemistry (Huisgen cycloaddition). The incorporation of iridium complexes resulted in functional polymeric materials with potential applications in OLEDs, while the incorporation of flavin led to the formation of redox-active polymers that are potentially useful in electrochemically controlled molecular sensing and surface modification. ii) The click reaction between bisazides and bisalkynes has led to the formation of novel conjugated polymers that showed interesting luminescent properties and can potentially be used as thermally structurable organic semiconductors, ${ }^{[111,112]}$ while the poly-cycloaddition of a $\mathrm{AB}_{2}$ monomer resulted in hyperbranched polymers. ${ }^{[113]}$ Recently, Qing and co-workers reported fluoropolymers formed by poly(cycloaddition) that showed good thermal stability and solubility in common organic solvents. ${ }^{[14]}$ iii) When combined with certain protection-deprotection strategies, Huisgen cycloaddition has also enabled access to a broad range of fragments useful for fragment-based drug discovery. ${ }^{[115]}$

While the framework of click chemistry includes range of different reactions, the herein presented work has focused on 1,3-dipolar ${ }^{[116]}$ and [4+2] (Diels-Alder) cycloadditions. ${ }^{[17]}$ Both methods have their individual strengths: the Huisgentype reactions are often fast and the reaction partners are exceptionally stable under a wide range of reaction conditions, while the Diels-Alder reactions do not involve catalysts and can often be used under physiological conditions without further purification. After this manuscript was accepted for publication, numerous articles have been published in this ever expanding field of research. ${ }^{[18-123]}$

Far beyond the selected examples included herein, click chemistry has converged into an important tool set for materials scientists, and it is not difficult to predict that the range of potential applications, especially in the life sciences, will continue to grow. On the other hand, it can be expected that the continuous push for designer materials will lead to the identification of additional chemical reactions that can be reframed within the concept of click chemistry; a framework of chemical versatility and control.

Received: November 30, 2006 Published online: August 9, 2007

[1] C. J. Hawker, K. L. Wooley, Science 2005, 309, 1200.

[2] H. C. Kolb, M. G. Finn, K. B. Sharpless, Angew. Chem. Int. Ed. 2001, 40, 2004.

[3] P. Wu, A. K. Feldman, A. K. Nugent, C. J. Hawker, A. Scheel, B. Voit, J. Pyun, J. M. J. Frechet, K. B. Sharpless, V. V. Fokin, Angew. Chem. Int. Ed. 2004, 43, 3928.
[4] Q. Wang, T. R. Chan, R. Hilgraf, V. V. Fokin, K. B. Sharpless, M. G. Finn, J. Am. Chem. Soc. 2003, 125, 3192.

[5] D. D. Diaz, S. Punna, P. Holzer, A. K. McPherson, K. B. Sharpless, V. V. Fokin, M. G. Finn, J. Polym. Sci., Part A 2004, 42, 4392.

[6] S. Punna, E. Kaltgrad, M. G. Finn, Bioconjugate Chem. 2005, 16, 1536.

[7] S. Punna, J. Kuzelka, Q. Wang, M. G. Finn, Angew. Chem. Int. Ed. 2005, 44, 2215.

[8] J. A. Johnson, D. R. Lewis, D. D. Diaz, M. G. Finn, J. T. Koberstein, N. J. Turro, J. Am. Chem. Soc. 2006, 128, 6564.

[9] C. Li, M. G. Finn, J. Polym. Sci., Part A 2006, 44, 5513

[10] R. J. Thibault, K. Takizawa, P. Lowenheilm, B. Helms, J. L. Mynar, J. M. J. Frechet, C. J. Hawker, J. Am. Chem. Soc. 2006, 128, 12084.

[11] M. J. Joralemon, R. K. O'Reilly, J. B. Matson, A. K. Nugent, C. J. Hawker, K. L. Wooley, Macromolecules 2005, 38, 5436.

[12] M. J. Joralemon, R. K. O'Reilly, C. J. Hawker, K. L. Wooley, J. Am. Chem. Soc. 2005, 127, 16892.

[13] M. Malkoch, R. Vestberg, N. Gupta, L. Mespouille, P. Dubois, A. F. Mason, J. L. Hedrick, Q. Liao, C. W. Frank, K. Kingsbury, C. J. Hawker, Chem. Commun. 2006, 2774.

[14] P. Wu, M. Malkoch, J. N. Hunt, R. Vestberg, E. Kaltgrad, M. G. Finn, V. V. Fokin, K. B. Sharpless, C. J. Hawker, Chem. Commun. 2005, 5775 .

[15] M. Malkoch, K. Schleicher, E. Drockenmuller, C. J. Hawker, T. P. Russell, P. Wu, V. V. Fokin, Macromolecules 2005, 38, 3663.

[16] M. Malkoch, R. J. Thibault, E. Drockenmuller, M. Messerschmidt, B. Voit, T. P. Russell, C. J. Hawker, J. Am. Chem. Soc. 2005, 127, 14942.

[17] H. Li, F. Cheng, A. M. Duft, A. Adronov, J. Am. Chem. Soc. 2005, $127,14518$.

[18] J. L. Delgado, P. de la Cruz, F. Langa, A. Urbina, J. Casado, J. T. L. Navarrete, Chem. Commun. 2004, 1734.

[19] R. Zirbs, F. Kienberger, P. Hinterdorfer, W. H. Binder, Langmuir $\mathbf{2 0 0 5}, 21,8414$.

[20] M. Proupin-Perez, R. Cosstick, L. M. Liz-Marzan, V. SalgueirinoMaceira, M. Brust, Nucleosides, Nucleotides Nucleic Acids 2005, 24, 1075.

[21] D. A. Fleming, C. J. Thode, M. E. Williams, Chem. Mater. 2006, 18, 2327.

[22] J. L. Brennan, N. S. Hatzakis, T. R. Tshikhudo, N. Dirvianskyte, V. Razumas, S. Patkar, J. Vind, A. Svendsen, R. J. M. Nolte, A. E. Rowan, M. Brust, Bioconjugate Chem. 2006, 17, 1373.

[23] W. H. Binder, R. Zirbs, F. Kienberger, P. Hinterdorfer, Polym. Adv. Technol. 2006, 17, 754.

[24] M. A. White, J. A. Johnson, J. T. Koberstein, N. J. Turro, J. Am. Chem. Soc. 2006, 128, 11356.

[25] A. Ulman, Chem. Rev. 1996, 96, 1533.

[26] J. P. Collman, N. K. Devaraj, C. E. D. Chidsey, Langmuir 2004, 20, 1051.

[27] N. K. Devaraj, G. P. Miller, W. Ebina, B. Kakaradov, J. P. Collman, E. T. Kool, C. E. D. Chidsey, J. Am. Chem. Soc. 2005, 127, 8600

[28] J. K. Lee, Y. S. Chi, I. S. Choi, Langmuir 2004, 20, 3844.

[29] J. P. Collman, N. K. Devaraj, T. P. A. Eberspacher, C. E. D. Chidsey, Langmuir 2006, 22, 2457.

[30] B. S. Lee, J. K. Lee, W.-J. Kim, Y. H. Jung, S. J. Sim, J. Lee, I. S. Choi, Biomacromolecules 2007, 8, 744.

[31] Y. Zhang, S. Z. Luo, Y. J. Tang, L. Yu, K. Y. Hou, J. P. Cheng, X. Q. Zeng, P. G. Wang, Anal. Chem. 2006, 78, 2001.

[32] M. N. Yousaf, B. T. Houseman, M. Mrksich, Proc. Natl. Acad. Sci. USA 2001, 98,5992

[33] W. S. Dillmore, M. N. Yousaf, M. Mrksich, Langmuir 2004, 20, 7223.

[34] D. I. Rozkiewicz, D. Janczewski, W. Verboom, B. J. Ravoo, D. N. Reinhoudt, Angew. Chem. Int. Ed. 2006, 45, 5292.

[35] N. J. Agard, J. A. Prescher, C. R. Bertozzi, J. Am. Chem. Soc. 2004, $126,15046$. 
[36] W. S. Yeo, M. N. Yousaf, M. Mrksich, J. Am. Chem. Soc. 2003, 125, 14994.

[37] M. N. Yousaf, M. Mrksich, J. Am. Chem. Soc. 1999, 121, 4286.

[38] M. N. Yousaf, B. T. Houseman, M. Mrksich, Angew. Chem. Int. Ed. 2001, 40, 1093.

[39] X.-L. Sun, C. L. Stabler, C. S. Cazalis, E. L. Chaikof, Bioconjugate Chem. 2006, 17, 52.

[40] K. W. Hill, J. Taunton-Rigby, J. D. Carter, E. Kropp, K. Vagle, W. Pieken, D. P. C. McGee, G. M. Husar, M. Leuck, D. J. Anziano, D. P. Sebesta, J. Org. Chem. 2001, 66, 5352.

[41] V. Pozsgay, N. E. Vieira, A. Yergey, Org. Lett. 2002, 4, 3191.

[42] A. Dantas de Araujo, J. M. Palomo, J. Cramer, M. Koehn, H. Schroeder, R. Wacker, C. Niemeyer, K. Alexandrov, H. Waldmann, Angew. Chem. Int. Ed. 2006, 45, 296.

[43] H. A. Latham-Timmons, A. Wolter, J. S. Roach, R. Giare, M. Leuck, Nucleosides, Nucleotides Nucleic Acids 2003, 22, 1495.

[44] T. Liebert, C. Haensch, T. Heinze, Macromol. Rapid Commun. 2006 , $27,208$.

[45] J. Hafren, W. Zou, A. Cordova, Macromol. Rapid Commun. 2006, $27,1362$.

[46] J. Gierlich, G. A. Burley, P. M. E. Gramlich, D. M. Hammond, T. Carell, Org. Lett. 2006, 8, 3639.

[47] B. P. Duckworth, J. H. Xu, T. A. Taton, A. Guo, M. D. Distefano, Bioconjugate Chem. 2006, 17, 967.

[48] F. Fazio, M. C. Bryan, O. Blixt, J. C. Paulson, C.-H. Wong, J. Am. Chem. Soc. 2002, 124, 14397.

[49] M. C. Bryan, F. Fazio, H. K. Lee, C. Y. Huang, A. Chang, M. D. Best, D. A. Calarese, C. Blixt, J. C. Paulson, D. Burton, I. A. Wilson, C. H. Wong, J. Am. Chem. Soc. 2004, 126, 8640.

[50] J.-C. Meng, G. Siuzdak, M. G. Finn, Chem. Commun. 2004, 2108.

[51] J.-C. Meng, C. Averguj, W. G. Lewis, G. Siuzdak, M. G. Finn, Angew. Chem. Int. Ed. 2004, 43, 1255.

[52] H. Nandivada, H. Y. Chen, L. Bondarenko, J. Lahann, Angew. Chem. Int. Ed. 2006, 45, 3360.

[53] G. K. Such, J. F. Quinn, A. Quinn, E. Tjipto, F. Caruso, J. Am. Chem. Soc. 2006, 128, 9318.

[54] W. H. Binder, C. Kluger, Curr. Org. Chem. 2006, 10, 1791.

[55] J. W. Lee, B.-K. Kim, H. J. Kim, S. C. Han, W. S. Shin, S.-H. Jin, Macromolecules 2006, 39, 2418.

[56] J. W. Lee, B.-K. Kim, J. H. Kim, W. S. Shin, S.-H. Jin, J. Org. Chem. 2006, $71,4988$.

[57] J. W. Lee, J. H. Kim, B.-K. Kim, Tetrahedron Lett. 2006, 47, 2683.

[58] J. W. Lee, J. H. Kim, B.-K. Kim, J. H. Kim, W. S. Shin, S.-H. Jin, Tetrahedron 2006, 62, 9193.

[59] J. W. Lee, J. H. Kim, B.-K. Kim, W. S. Shin, S.-H. Jin, Tetrahedron 2006, 62, 894.

[60] D. T. S. Rijkers, G. W. van Esse, R. Merkx, A. J. Brouwer, H. J. F. Jacobs, R. J. Pieters, R. M. J. Liskamp, Chem. Commun. 2005, 4581.

[61] E. Fernandez-Megia, J. Correa, I. Rodriguez-Meizoso, R. Riguera, Macromolecules 2006, 39, 2113.

[62] J. R. McElhanon, D. R. Wheeler, Org. Lett. 2001, 3, 2681.

[63] C. Kim, H. Kim, K. Park, J. Organomet. Chem. 2003, 667, 96.

[64] C. Kim, H. Kim, K. Park, J. Organomet. Chem. 2005, 690, 4794.

[65] C. Kim, K. I. Lim, C. G. Song, J. Organomet. Chem. 2005, 690, 3278.

[66] G. Mihov, I. Scheppelmann, K. Mullen, J. Org. Chem. 2004, 69, 8029.

[67] G. Mihov, D. Grebel-Koehler, A. Lubbert, G. W. M. Vandermeulen, A. Herrmann, H. A. Klok, K. Mullen, Bioconjugate Chem. 2005, 16, 283.

[68] B. C. Englert, S. Bakbak, U. H. F. Bunz, Macromolecules 2005, 38, 5868.

[69] A. D. Thomsen, E. Malmstrom, S. Hvilsted, J. Polym. Sci., Part A 2006, 44, 6360 .

[70] H. Durmaz, A. Dag, O. Altintas, T. Erdogan, G. Hizal, U. Tunca, Macromolecules 2007, 40, 191.

[71] R. Riva, S. Schmeits, F. Stoffelbach, C. Jerome, R. Jerome, P. Lecomte, Chem. Commun. 2005, 5334.
[72] B. Parrish, R. B. Breitenkamp, T. Emrick, J. Am. Chem. Soc. 2005, 127, 7404

[73] P. Lecomte, R. Riva, S. Schmeits, J. Rieger, K. Van Butsele, C. Jerome, R. Jerome, Macromol. Symp. 2006, 240, 157.

[74] R. Hoogenboom, B. C. Moore, U. S. Schubert, Chem. Commun. 2006, 4010 .

[75] W. H. Binder, C. Kluger, Macromolecules 2004, 37, 9321.

[76] R. Luxenhofer, R. Jordan, Macromolecules 2006, 39, 3509.

[77] R. K. O'Reilly, M. J. Joralemon, K. L. Wooley, C. J. Hawker, Chem. Mater. 2005, 17, 5976.

[78] R. K. O'Reilly, M. J. Joralemon, C. J. Hawker, K. L. Wooley, Chem. Eur. J. 2006, 12, 6776

[79] R. K. O'Reilly, M. J. Joralemon, C. J. Hawker, K. L. Wooley, J. Polym. Sci., Part A 2006, 44, 5203.

[80] S. R. Gondi, A. P. Vogt, B. S. Sumerlin, Macromolecules 2007, 40, 474.

[81] H. Gao, G. Louche, B. S. Sumerlin, N. Jahed, P. Golas, K. Matyjaszewski, Macromolecules 2005, 38, 8979.

[82] J.-F. Lutz, H. G. Boerner, K. Weichenhan, Macromol. Rapid Commun. 2005, 26, 514.

[83] J.-F. Lutz, H. G. Boerner, K. Weichenhan, Macromolecules 2006, 39 , 6376.

[84] G. Mantovani, V. Ladmiral, L. Tao, D. M. Haddleton, Chem. Commun. 2005, 2089.

[85] N. V. Tsarevsky, B. S. Sumerlin, K. Matyjaszewski, Macromolecules $\mathbf{2 0 0 5}, 38,3558$.

[86] J. A. Opsteen, J. C. M. van Hest, Chem. Commun. 2005, 57.

[87] H. Gao, K. Matyjaszewski, Macromolecules 2006, 39, 4960.

[88] M. R. Whittaker, C. N. Urbani, M. J. Monteiro, J. Am. Chem. Soc. 2006, 128,11360 .

[89] A. P. Vogt, B. S. Sumerlin, Macromolecules 2006, 39, 5286.

[90] B. A. Laurent, S. M. Grayson, J. Am. Chem. Soc. 2006, 128, 4238.

[91] V. Ladmiral, G. Mantovani, G. J. Clarkson, S. Cauet, J. L. Irwin, D. M. Haddleton, J. Am. Chem. Soc. 2006, 128, 4823.

[92] B. S. Sumerlin, N. V. Tsarevsky, G. Louche, R. Y. Lee, K. Matyjaszewski, Macromolecules 2005, 38, 7540.

[93] H. Durmaz, B. Colakoclu, U. Tunca, G. Hizal, J. Polym. Sci., Part A 2006, 44, 1667.

[94] H. Durmaz, F. Karatas, U. Tunca, G. Hizal, J. Polym. Sci., Part A 2006, 44,499 .

[95] H. Durmaz, F. Karatas, U. Tunca, G. Hizal, J. Polym. Sci., Part A 2006, 44, 3947.

[96] D. A. Ossipov, J. Hilborn, Macromolecules 2006, 39, 1709

[97] Y. Chujo, K. Sada, T. Saegusa, Macromolecules 1990, 23, 2636.

[98] Y. Imai, H. Itoh, K. Naka, Y. Chujo, Macromolecules 2000, 33, 4343.

[99] J. D. Luo, M. Haller, H. X. Li, T. D. Kim, A. K. Y. Jen, Adv. Mater. 2003, 15, 1635.

[100] J. R. Jones, C. L. Liotta, D. M. Collard, D. A. Schiraldi, Macromolecules 1999, 32, 5786

[101] M. Vargas, R. M. Kriegel, D. M. Collard, D. A. Schiraldi, J. Polym. Sci., Part A 2002, 40, 3256.

[102] E. Ishow, J. Bouffard, Y. Kim, T. M. Swager, Macromolecules 2006, $39,3202$.

[103] T. D. Kim, J. D. Luo, Y. Q. Tian, J. W. Ka, N. M. Tucker, M. Haller, J. W. Kang, A. K. Y. Jen, Macromolecules 2006, 39, 1676.

[104] B. Gacal, H. Durmaz, M. A. Tasdelen, G. Hizal, U. Tunca, Y. Yagci, A. L. Demirel, Macromolecules 2006, 39, 5330.

[105] C. Gousse, A. Gandini, P. Hodge, Macromolecules 1998, 31, 314.

[106] R. Gheneim, C. Perez-Berumen, A. Gandini, Macromolecules 2002, $35,7246$.

[107] X. X. Chen, M. A. Dam, K. Ono, A. Mal, H. B. Shen, S. R. Nutt, K. Sheran, F. Wudl, Science 2002, 295, 1698.

[108] B. Gotsmann, U. Duerig, J. Frommer, C. J. Hawker, Adv. Funct. Mater. 2006, 16, 1499.

[109] X.-Y. Wang, A. Kimyonok, M. Weck, Chem. Commun. 2006, 3933. 
[110] J. B. Carroll, B. J. Jordan, H. Xu, B. Erdogan, L. Lee, L. Cheng, C. Tiernan, G. Cooke, V. M. Rotello, Org. Lett. 2005, 7, 2551.

[111] D. J. V. C. van Steenis, O. R. P. David, G. P. F. van Strijdonck, J. H. van Maarseveen, J. N. H. Reek, Chem. Commun. 2005, 4333.

[112] S. Bakbak, P. J. Leech, B. E. Carson, S. Saxena, W. P. King, U. H. F. Bunz, Macromolecules 2006, 39, 6793.

[113] A. J. Scheel, H. Komber, B. I. Voit, Macromol. Rapid Commun. 2004, 25, 1175.

[114] Y. Zhu, Y. Huang, W.-D. Meng, H. Li, F.-L. Qing, Polymer 2006, 47, 6272.

[115] O. D. Montagnat, G. Lessene, A. B. Hughes, Tetrahedron Lett. 2006, 47, 6971.

[116] V. D. Bock, H. Hiemstra, J. H. van Maarseveen, Eur. J. Org. Chem. 2006, 51.
[117] C. J. Li, Chem. Rev. 2005, 105, 3095.

[118] Q. Zeng, T. Li, B. Cash, S. Li, F. Xie, Q. Wang, Chem Commun 2007, 1453.

[119] J.-F. Lutz, Angew. Chem., Int. Ed. 2007, 46, 1018.

[120] B. S. Lee, J. K. Lee, W. J. Kim, Y. H. Jung, S. J. Sim, J. Lee, I. S. Choi, Biomacromolecules 2007, 8, 744 .

[121] V. Crescenzi, L. Cornelio, C. D. Meo, S. Nardecchia, R. Lamanna, Biomacromolecules 2007, 8, 1844.

[122] W. H. Binder, R. Sachsenhofer, Macromol. Rapid Commun. 2007, 28,15 .

[123] N. J. Agard, J. M. Baskin, J. A. Prescher, A. Lo, C. R. Bertozzi, ACS Chem. Biol. 2006, 1, 644. 